\title{
"One Pot” Two-Step Synthesis of Aryl Sulfur Compounds by Photoinduced Reactions of Thiourea Anion with Aryl Halides
}

\author{
Juan E. Argüello, Luciana C. Schmidt and Alicia B. Peñéñory*
}

\section{General methods and materials}

Methods: Irradiation was conducted with a $125-\mathrm{W}$ medium pressure Hg lamp emitting maximally at $365 \mathrm{~nm}$ (Applied Photophysics Limited). ${ }^{1} \mathrm{H}$ and ${ }^{13} \mathrm{C}$ NMR spectra were recorded at 200 and $50 \mathrm{MHz}$ respectively on a Brucker AC-200 spectrometer, and all spectra are reported in $\delta(\mathrm{ppm})$ relative to $\mathrm{Me}_{4} \mathrm{Si}$, with $\mathrm{CDCl}_{3}$ as solvent. Gas chromatographic analyses were performed on a Hewlett Packard 6890 A with a flame-ionization detector, on a HP-5 $30 \mathrm{~m}$ capillary column of a $0.32 \mathrm{~mm}$ x $0.25 \mu \mathrm{m}$ film thickness, or a HP1 $5 \mathrm{~m} \times 0.53 \times 2.65 \mu \mathrm{m}$ film thickness column. GS/MS analyses were carried out on a Shimadzu GC-MS QP 5050 spectrometer, employing a $25 \mathrm{~m}$ x $0.2 \mathrm{~mm}$ x $0.33 \mu \mathrm{m}$ HP-5 column.

Materials: tert-BuOK, thiourea, the aryl halides, naphthalene, DTBN, thioanisole, diphenyl sulfide, 1methoxy-4-(methylthio)benzene, 4-(methylthio)nitrobenzene and 4-(methylthio)benzonitrile were all high purity commercial samples which were used without further purification. DMSO, DMF, HMPA, $\mathrm{MeCN}$ were purified by standard procedures and stored over molecular sieves (4 $\mathrm{A})$. EtOH absolute grade was used without further purification. The thiourea anion (1) was generated in situ by acid-base deprotonation using tert-BuOK. All the products are known and exhibited physical properties identical to those reported in the literature. Also, they were isolated by radial chromatography from the reaction mixture and characterized by ${ }^{1} \mathrm{H}$ and ${ }^{13} \mathrm{C}$ NMR and mass spectrometry.

4-(Mercapto)benzophenone: to a solution of 4-benzoylbenzene thiolate obtained from $10.5 \mathrm{mmol}$ of ter-BuOK, $10 \mathrm{mmol}$ of the thiourea and $0.5 \mathrm{mmol}$ of the bromobenzophenone in $10 \mathrm{~mL}$ of DMSO (according to the general procedure described), $10 \mathrm{~mL}$ of a $\mathrm{NH}_{4} \mathrm{NO}_{3}$ saturated solution was added and then acidification with $0.3 \mathrm{~mL}$ of $\mathrm{HCl}(37 \%)$ until decoloration of the solution $(\mathrm{pH} \cong 2)$. The mixture was extracted with ethyl ether $(3 \times 20 \mathrm{~mL})$, the organic extract was washed twice with water, dried and the 4-(mercapto)benzophenone was isolated by radial chromatography $(85.6 \mathrm{mg}, 80 \%)$ and its physical properties were similar to the reported in literature. ${ }^{1}$ 
Bis(4-benzoylphenyl) disulfide: to a solution of 4-benzoylbenzene thiolate obtained from $10.5 \mathrm{mmol}$ of ter-BuOK, $10 \mathrm{mmol}$ of the thiourea and $0.5 \mathrm{mmol}$ of the bromobenzophenone in $10 \mathrm{~mL}$ of DMSO (according to the general procedure described). A mixture of iodine $(0.13 \mathrm{gr}, 0.51 \mathrm{mmol})$ and potassium iodide $(0.25 \mathrm{gr}, 1.5 \mathrm{mmol})$ was added and then the mixture stirred until the dark brown color disappeared. $30 \mathrm{~mL}$ of water was added and the mixture was acidificated with $0.3 \mathrm{~mL}$ of $\mathrm{HCl}(37 \%)$ and then extracted with ethyl ether $(3 \times 20 \mathrm{~mL})$. The organic extract was washed twice with water, dried and the bis(4-benzoylphenyl) disulfide was isolated by radial chromatography $(74.8 \mathrm{mg}, 70 \%)$ and its physical properties were similar to the reported in literature. ${ }^{1}$

4-(Phenylthio)benzophenone: to a solution of 4-benzoylbenzene thiolate obtained from $10.5 \mathrm{mmol}$ of ter-BuOK, $10 \mathrm{mmol}$ of the thiourea and $0.5 \mathrm{mmol}$ of the bromobenzophenone in $10 \mathrm{~mL}$ of DMSO (according to the general procedure described), $2.5 \mathrm{mmol}$ of $t e r$-BuOK and $40 \mathrm{mmol}$ of IPh were added and the reaction mixture irradiated for $3 \mathrm{~h}$. The reaction was quenched with addition of methyl iodide ( 6 equiv) and $30 \mathrm{~mL}$ of water, and then the mixture was extracted with methylene chloride $(3 \times 20$ $\mathrm{mL}$ ). The organic extract was washed twice with water, dried and the 4-phenylthiobenzophenone (35\%) was quantified by GLC with the internal standard method.

Registry No. 1-(methylthio)naphthalene, ${ }^{2}$ [10075-72-6]; 2-(methylthio)naphthalene, ${ }^{3}$ [7433-79-6]; bis(1-naphthyl) sulfide, ${ }^{4 \mathrm{a}}$ [607-53-4]; bis(2-naphthyl) sulfide, ${ }^{4 \mathrm{~b}}$ [613-81-0]; 2-(methylthio)pyridine, ${ }^{5}$ [18438-38-5]; 3-(methylthio)pyridine, ${ }^{6}$ [18794-33-7]; 2-(methylthio)quinoline, ${ }^{6}$ [40279-26-3]; 2(methylthio)pyrazine, ${ }^{7}$ [21948-70-9]; 2-(methylthio)pyrimidine, ${ }^{8}$ [823-09-6]; 2 (methylthio)acetophenone, ${ }^{9}$ [1441-97-0]; 4-(methylthio)benzophenone, ${ }^{10}$ [23405-48-3]; 4(phenylthio)benzophenone, ${ }^{11}$ [6317-78-8]; 4-(mercapto)benzophenone, ${ }^{12}$ [1620-94-6]; bis(4benzoylphenyl) disulfide, ${ }^{1}$ 1,4-bis(methylthio)benzene, ${ }^{13}$ [699-20-7]; bis[4-(methylthio)phenyl] sulfide, ${ }^{13}$ [125877-23-8]; bis(3-pyridyl) sulfide, ${ }^{14}$ [57331-00-7]; bis(2-pyridyl) sulfide, ${ }^{15}$ [4262-06-0].

\section{References}

${ }^{1}$ Walker, D.; Leib, J. J. Org. Chem. 1963, 28, 3077-3082.

${ }^{2}$ Gilman, H.; Webb, F. J. J. Am. Chem. Soc. 1949, 71, 4062-4066.

${ }^{3}$ Buu-Hoi, Ng. Ph.; Hoán, Ng.; Lavit, D. J. Chem. Soc. 1953, 485-489. Jacques, J. Bull. Soc. Chim. France, 1955, 231-236.

4 (a) Hauptmann, H.; Wladislaw, B. J. Am. Chem. Soc. 1950, 72, 710-712. (b) ibid 707-709.

${ }^{5}$ Fry, D. J.; Kendall, J. P. J. Chem. Soc. 1951, 1716-1722.

${ }^{6}$ Albert, A.; Barlin, G. B. J. Chem. Soc. 1959, 2384-2396.

${ }^{7}$ Cheeseman, G. W. H. J. Chem. Soc. 1960, 242-247.

${ }^{8}$ Matsukawa, T.; Ohta, B. J. Pharm. Soc. Japan 1949, 69, 489-491. 
${ }^{9}$ Crawford, R. J.; Woo, C. J. Org. Chem. 1966, 31, 1055-1056.

${ }^{10}$ Mustafá, A. J. Chem. Soc. 1949, 352-355.

${ }^{11}$ Dilthey, W.; Neuhaus, L.; Reis, E.; Schommer, W. J. Prakt. Chem. 1930, 124, 81-126.

${ }^{12}$ Schellenberg, K. A.; Westheimer, F. H. J. Org. Chem. 1965, 30, 1859-1862.

${ }^{13}$ Kobayashi, K.; Koyama, E.; Namatame, K.; Kitaura, T.; Kono, C.; Goto, M.; Obinata, T.; Furukawa, N. J. Org. Chem. 1999, 64, 3190-3195.

${ }^{14}$ Combellas, C.; Dellerue, S.; Mathey, G.; Thiébault, A. Tetrahedron Lett. 1997, 38, 539-542.

${ }^{15}$ Grassetti, D. R.; Brokke, M. E.; Murray Jr., J. F. J. Med. Chem. 1965, 8, 753-756. 